\title{
Color changes, nitrite content, and rehydration capacity of edible bird's nest by advanced drying method
}

\begin{abstract}
This article presents the authors' first attempt to improve quality of edible bird's nest through continuous and intermittent low-temperature drying $\left(25\right.$ and $\left.40^{\circ} \mathrm{C}\right)$ with infrared and ultraviolet $\mathrm{C}$ (UVC) treatments. The attributes of quality were compared in regard to quality of hot-air-dried samples at $70-90^{\circ} \mathrm{C}$. Experimental results showed that a significant improvement in the quality of edible bird's nest in terms of minimizing color changes and rehydration capacity using intermittent low-temperature drying with infrared and UVC drying profile. However, it was also found that any drying method has less significant effect on the nitrite content of edible bird's nest.
\end{abstract}

Keyword: Color change; Edible bird's nest; Intermittent low-temperature drying with infrared and UVC treatments; Nitrite content change; Rehydration capacity 